\title{
Identificação dos Resíduos Sólidos Gerados nos Laboratórios de Ensino e Pesquisa da UFFS - Campus Chapecó para elaboração de Plano de Gerenciamento de Resíduos Sólidos
}

\author{
Identification of Solid Waste Generated in the Teaching and Research Laboratories \\ of UFFS - Chapecó Campus to elaborate Solid Waste Management Plan
}

\author{
Luana Taize Mello $\left.{ }^{1 *}\right)$ \\ Celsiane Teilonara Ziliotto² \\ Rosiléa Garcia França ${ }^{3}$ \\ Leandro Bordin 4
}

\section{Resumo}

O presente trabalho teve o objetivo de realizar a identificação dos resíduos gerados nos laboratórios provisórios e definitivos, de ensino e pesquisa, da Universidade Federal da Fronteira Sul (UFFS) - Campus Chapecó em função dos procedimentos realizados, bem como a forma de manejo desses resíduos a fim de, posteriormente, elaborar um Plano de Gerenciamento de Resíduos Sólidos (PGRS). Este trabalho teve como uma de suas metas servir de referência para a implantação de um PGRS em todos os campi da Universidade, tendo em vista que a Universidade era de recente criação, alguns laboratórios estavam funcionando em locais provisórios e os demais estavam em fase de construção durante a realização desta pesquisa. $O$ trabalho foi desenvolvido com base na elaboração de um questionário, o qual foi aplicado aos professores responsáveis por cada laboratório da Instituição. A partir dos resultados obtidos com a aplicação dos questionários, elaborou-se um mapa com a classificação dos resíduos identificados. $\mathrm{O}$ resultado final da pesquisa foi a elaboração de um documento, o Plano de Gerenciamento de Resíduos Sólidos, no qual foram propostas as diretrizes necessárias para o manejo desses resíduos. Este trabalho procurou envolver os responsáveis pelos laboratórios de modo a gerar nestes uma preocupação com o gerenciamento correto dos resíduos e uma consciência ambiental, promovendo assim a saúde pública e a proteção ao meio ambiente. Percebeu-se que muitos deles tinham dúvidas quanto à forma correta de realizar o manejo dos resíduos; além disso, verificaram-se problemas no gerenciamento dos resíduos gerados nos laboratórios em funcionamento, devido às instalações provisórias em que foram montados.

Palavras-chave: manejo; meio ambiente; saúde.

\section{Abstract}

This present work aimed to identify the residues generated in the provisional and definitive teaching and research laboratories of the Federal University of Southern

I Engenheira Ambiental; Universidade Federal da Fronteira Sul, UFFS; Endereço: Rua Marechal Floriano Peixoto, 700, Centro, CEP: 8980I-50I, Chapecó-SC, Brasil; Email: lu.taize@gmail.com (*) Autor para correspondência

2 Engenheira Ambiental; Universidade Federal da Fronteira Sul, UFFS; Chapecó, Brasil; E-mail: celsianeziliotto@yahoo.com.br

3 Dra.; Engenheira Civil; Professora da Universidade Federal da Fronteira Sul, UFFS, Campus Chapecó; Endereço:Avenida Fernando Machado, 108 E, Centro, CEP: 89802-I I2, Chapecó-SC, Brasil; E-mail: rosilea.franca@uffs.edu.br

4 Dr.; Educação Científica e Tecnológica; Professor da Universidade Federal da Fronteira Sul, UFFS. Campus Chapecó; Endereço: SC-459, km 2, s/n, CEP: 89802-265, Chapecó-SC, Brasil; E-Mail: Ibordin@uffs.edu.br Recebido para publicação em 16/11/2016 e aceito em II/II/2019

\begin{tabular}{llllll}
\hline Ambiência & Guarapuava (PR) & v.l5 n.2 & p. 389 - 402 & Maio/Ago 2019 & ISSN 1808 - 025I
\end{tabular}


Frontier (UFFS) - Chapecó Campus according to the procedures performed, as well as the way of handling these residues, to subsequently develop a Solid Waste Management Plan (PGRS). One of its goals was to serve as a reference for the implementation of a PGRS in all University campuses. Given that the University was recently established, some laboratories were operating at provisional places and others were under construction during this research. The work was developed based on the elaboration of a questionnaire, which was applied to the teachers responsible for each laboratory of the Institution. From the results obtained with the application of the questionnaires, a map was prepared with the classification of the identified residues. The final result of the research was the elaboration of a document, the Solid Waste Management Plan, which proposed the necessary guidelines for the management of this waste. This work sought to involve those responsible for the laboratories in order to generate in them a concern with the correct management of waste and an environmental awareness, thus promoting public health and protection of the environment. It was noticed that many of them had doubts as to the correct way to carry out the waste management. In addition, there were problems in the management of the waste generated in the laboratories in operation due to the temporary facilities in which they were assembled.

Keywords: management; environment; health.

\section{Introdução}

Os resíduos sólidos são definidos como todo material, substância, objeto ou bem descartado no estado sólido e semissólido, proveniente de atividades humanas em sociedade (BRASIL, 2010). O crescente aumento na produção e destinação incorreta dos resíduos tem impactado diretamente no alto nível de degradação ambiental e na ocorrência de diversos problemas de saúde pública. Como forma de reverter essa situação, espera-se que a sociedade aja com responsabilidade em suas escolhas e atitudes, pensando nas consequências que elas podem acarretar para as presentes e futuras gerações (ALBUQUERQUE et al., 2010).

As universidades enquanto geradoras de resíduos sólidos e frente à importância que representam perante a sociedade, como espaço de reflexão crítica e formação de novos profissionais, precisam se preocupar com o correto gerenciamento dos seus resíduos, de modo a atuar de forma exemplar em relação ao seu compromisso com a preservação ambiental e servir de referência para a comunidade acadêmica e externa (VENTURI; PEREIRA, 2015).

Muitas universidades têm se deparado com inúmeros problemas relacionados ao tratamento e à disposição final dos resíduos gerados em seus laboratórios de ensino e pesquisa, uma vez que esses resíduos diferenciam-se daqueles gerados em unidades industriais por apresentarem baixo volume, mas grande diversidade de composições, o que dificulta a tarefa de estabelecer um tratamento e uma disposição final ambientalmente adequada para todos. Sendo assim, várias instituições utilizam práticas inadequadas em relação ao manejo de seus resíduos, como exemplo pode-se citar o estoque inapropriado de resíduos e o descarte nas pias dos laboratórios devido à falta de política institucional que permita um tratamento global do problema (GERBASE; COELHO; MACHADO, 2005).

Apesar das diversas dificuldades encontradas em relação ao manejo de seus resíduos, sabe-se que inúmeras universidades demonstram preocupação com a questão, tendo iniciado o 
correto gerenciamento dos mesmos, a fim de minimizar os impactos gerados por suas atividades (NOLASCO; TAVARES; BENDASSOLLI, 2006; BRASIL, 2010).

Para o adequado destino dos resíduos é imprescindível definir um Plano de Gerenciamento de Resíduos Sólidos (PGRS), documento que orienta sobre todos os processos relacionados as etapas de manejo dos resíduos e auxilia na sensibilização da comunidade acadêmica quanto às ações individuais e coletivas, propiciando assim segurança para a saúde pública e para o meio ambiente. A identificação dos resíduos é a primeira etapa para a elaboração de um PGRS, visto a necessidade de se conhecer o que é produzido para depois pensar nas demais etapas que envolvem esse processo, as quais são: segregação, identificação das embalagens, acondicionamento, armazenamento interno e externo, coleta e transporte interno e externo, tratamento, destinação e disposição final (MESQUITA; SARTORI; FIUZA, 2011).

O presente trabalho foi desenvolvido pelo Grupo de Estudos e Pesquisas em Saneamento Ambiental (GEPESA), o qual tem a finalidade de desenvolver estudos e pesquisas na área de saneamento ambiental: gerenciamento de resíduos sólidos, tratamento de esgotos, tratamento e abastecimento de água, gestão de saúde pública, dentre outros. No âmbito do GEPESA, a linha de pesquisa em Resíduos Sólidos e Impactos Ambientais propõe-se estudar e realizar pesquisas aplicadas ao manejo de resíduos sólidos, à minimização de resíduos e ao reaproveitamento e reciclagem dos mesmos.

A Universidade Federal da Fronteira Sul (UFFS) é de recente criação e no momento da pesquisa encontrava-se em fase de consolidação e construção de suas estruturas. No período de execução desta pesquisa os laboratórios que estavam em funcionamento encontravam-se em instalações provisórias e não possuíam um PGRS. Sendo assim, este trabalho teve o objetivo de realizar a identificação dos resíduos gerados nos laboratórios de ensino e pesquisa da UFFS Campus Chapecó em função dos procedimentos realizados, bem como a forma de manejo desses resíduos, a fim de, posteriormente, elaborar um PGRS a partir dos resultados encontrados.

\section{Material e Métodos}

No período de elaboração deste trabalho a UFFS - Campus Chapecó, possuía 39 laboratórios de ensino e pesquisa, dos quais apenas 6 estavam funcionando em locais provisórios e os demais estavam em fase de construção. Os laboratórios estudados pertencem às áreas: da saúde, da biologia, das engenharias, das ciências agrárias e das licenciaturas.

A metodologia de trabalho dividiu-se em 3 etapas:

\section{Identificação dos resíduos}

Nessa etapa foi realizado um mapeamento para identificação das características dos resíduos sólidos gerados pelos laboratórios em funcionamento e uma estimativa dos resíduos que seriam gerados nos demais laboratórios, através de entrevistas com os professores responsáveis por cada laboratório, os quais estavam definidos através da Portaria No 938/GR/UFFS/2012. Para isso, foi elaborado um questionário, a fim de identificar as matérias-primas (substâncias), as práticas (ensaios) realizadas e o manejo dos resíduos. Tendo em vista que se trata de uma pesquisa com seres humanos, o questionário foi previamente submetido à aprovação pelo Comitê de Ética em Pesquisa (CEP) da Universidade Comunitária da Região de Chapecó, sendo aprovado sob o registro no $194 / 12$. 
Inicialmente, o questionário seria aplicado para todos os professores responsáveis pelos laboratórios da Instituição, totalizando 39 questionários. Porém, devido a dificuldades encontradas para contatar alguns professores, foi possível aplicar o questionário somente para os responsáveis por 32 laboratórios.

Além disso, tendo em vista o recente funcionamento de 6 laboratórios em espaços provisórios, e os demais estarem em fase de construção, não foi possível estimar os resíduos de forma quantitativa, mas apenas qualitativa.

\section{Mapa de resíduos}

Com as informações obtidas a partir dos questionários aplicados, foi feita a tabulação dos dados, classificando os resíduos identificados conforme as normas da ABNT-NBR 10.004/2004 e da Resolução Conama n³58/2005, criando um Mapa de Resíduos.

\section{Plano de Gerenciamento de Resíduos Sólidos - PGRS}

A partir das informações obtidas nas etapas anteriores foi elaborado um PGRS, no qual constam os procedimentos adequados ao manejo (segregação,identificação, acondicionamento, armazenamento, coleta, transporte, tratamento, destinação/disposição final) de cada grupo de resíduos.

\section{Resultados e Discussão}

Através da primeira etapa da pesquisa foram identificados os resíduos químicos, biológicos, radioativos e comuns produzidos nos laboratórios provisórios da Universidade, bem como a estimativa dos que seriam produzidos nos laboratórios definitivos. Além disso, também foram verificadas algumas questões sobre como o manejo dos resíduos era realizado nos laboratórios provisórios, ou que procedimentos seriam adotados nos laboratórios definitivos, com o intuito de investigar como as novas Instituições de Ensino Superior têm procedido quanto ao descarte de seus resíduos.

Os resultados abaixo representam os laboratórios de todas as áreas: saúde, biologia, engenharias, ciências agrárias e licenciaturas, não sendo apresentado resultado específico para alguma das áreas citadas.

Conforme as entrevistas realizadas, a geração de resíduos sólidos nos 32 laboratórios pesquisados distribui-se conforme a Tabela 1.

\section{Tabela 1 - Distribuição da geração de resíduos.}

\begin{tabular}{cc}
\hline Tipo de resíduo & Número de laboratórios geradores \\
\hline Comum & 32 \\
Químico & 22 \\
Biológico & 15 \\
Radioativo & 0 \\
\hline
\end{tabular}

Fonte: do autor (2014)

Percebe-se a partir da tabela acima que 100\% dos laboratórios produzem resíduos comuns, aproximadamente $68 \%$ produzem resíduos químicos e $46 \%$ produzem resíduos biológicos. Nenhum deles produz resíduo radioativo. 
A partir da identificação dos tipos de resíduos gerados é possível propor medidas corretas para o gerenciamento dos mesmos. Sendo assim, durante as entrevistas percebeu-se a grande importância atribuída pelos professores a esta pesquisa, visto que muitos deles realmente não sabem a forma adequada de manejo a ser adotada para os resíduos gerados.

De acordo com os resultados obtidos a partir da tabulação dos dados, os resíduos identificados, bem como o manejo destinado a eles, serão apresentados a seguir:

\section{Resíduos químicos}

A Tabela 2 apresenta os resíduos químicos identificados nos laboratórios da Instituição, o que torna visível a grande variedade de resíduos produzidos em uma Universidade, confirmando o que foi dito anteriormente por Gerbase, Coelho e Machado (2005).

\section{Tabela 2 - Resíduos químicos.}

\begin{tabular}{cc}
\hline Tipo de resíduo & Número de laboratórios geradores \\
\hline Ácidos & 10 \\
Bases & 10 \\
Óxidos & 10 \\
Sais & 9 \\
Solventes e soluções orgânicas não halogenadas & 9 \\
Solventes e soluções orgânicas halogenadas & 8 \\
Soluções de metais & 5 \\
Fenóis & 5 \\
Peróxidos & 5 \\
Metais pesados & 4 \\
Amininas & 4 \\
Resíduos sólidos de inorgânicos perigosos & 4 \\
Mercúrio e seus sais & 3 \\
Resíduos de metais nobres & 3 \\
Óleos especiais & 2 \\
Tintas & 2 \\
Pesticidas & 1 \\
Cianetos & 1 \\
Resíduos sólidos de orgânicos perigosos & 0 \\
\hline
\end{tabular}

Fonte: do autor (2014)

Com exceção dos cianetos, todos os outros resíduos químicos presentes no questionário foram citados como resíduos gerados em algum laboratório da Universidade. Os resíduos mais citados foram os ácidos, bases e óxidos, sendo que aproximadamente 31\% dos laboratórios apresentam a geração desses resíduos. Também verificou-se a geração de sais e solventes/soluções de orgânicos não halogenados em cerca de $28 \%$ dos laboratórios.

Os laboratórios de Microbiologia, Física do Solo, Química do Solo e o laboratório de Uso, Manejo e Conservação do Solo indicaram a geração de resíduos orgânicos perigosos e/ou resíduos inorgânicos perigosos. 
Os metais pesados foram mencionados como resíduos dos seguintes laboratórios: Laboratório de Propagação, Melhoramento e Fisiologia Vegetal, Laboratório de Efluentes, Laboratório de Química do Solo e Laboratório de Uso, Manejo e Conservação do Solo.

Os laboratórios de Física do Solo, de Efluentes e de Hidroanálise citaram o mercúrio e seus sais como possíveis resíduos gerados. Os metais nobres foram mencionados como resíduos do laboratório de Química do Solo e do laboratório de Uso, Manejo e Conservação do Solo.

Essa grande variedade de resíduos produzidos, sendo grande parte deles perigosos, se não gerenciada da forma correta, pode acarretar uma contaminação química no ambiente em que esses resíduos forem dispostos, provocando possíveis danos à qualidade do ambiente e à saúde da população, devido à poluição ambiental causada por essa contaminação (FERNANDES; NUNES; PORTO, 2016).

\section{Resíduos Biológicos}

Os resíduos biológicos, ou seja, aqueles que apresentam agentes infecciosos, são classificados em grupos, em função de suas características, pela Resolução CONAMA No 358 de 2005: Grupos A, B, C, D e E. Os grupos B (resíduos que contêm substâncias químicas), C (resíduos que contenham radionuclídeos) e D (resíduos que podem ser equiparados aos resíduos domiciliares, resíduos comuns) não constaram na categoria "resíduos biológicos" apresentada no questionário, tendo em vista que já estavam inclusos em outras categorias específicas (BRASIL, 2005).

O grupo A representa os "resíduos com a possível presença de agentes biológicos que, por suas características de maior virulência ou concentração, podem apresentar risco de infecção" (BRASIL, 2005, p. 619). Segundo a Resolução CONAMA No 358 de 2005, esse grupo é subdividido em cinco categorias (A1, A2, A3, A4 e A5), as quais estão descritas abaixo conforme Brasil (2005):

Grupo A1: culturas de microrganismos; inóculos; resíduos de vacinação com microrganismos vivos ou atenuados; papeis, luvas e máscaras contaminadas; resíduos de laboratórios de manipulação genética; bolsas transfusionais contaminadas ou vencidas; sobras de amostras de laboratório contendo sangue ou líquidos corpóreos; entre outros.

Grupo A2: carcaças, peças anatômicas, vísceras e outros resíduos provenientes de animais submetidos à experimentação com inoculação de microrganismos, bem como suas forrações, e os cadáveres de animais suspeitos de portarem doenças epidemiológicas.

Grupo A3: peças anatômicas (membros) do ser humano, produto de fecundação sem sinais vitais menor que 500 gramas, $25 \mathrm{~cm}$ ou 20 semanas.

Grupo A4: filtros de ar e gases aspirados de área contaminada; alguns tipos de sobras de amostras de laboratório e seus recipientes contendo fezes, urina e secreções; carcaças, peças anatômicas, vísceras, resíduos provenientes de animais não inoculados de microrganismos, bem como suas forrações; bolsas transfusionais vazias ou resíduo pós-transfusão; entre outros.

Grupo A5: órgãos, tecidos, fluidos orgânicos, perfurocortantes ou escarificantes e demais materiais com suspeita de contaminação com príons.

Como mostra a Tabela 3, a classe de resíduos biológicos A1 foi a mais registrada durante as entrevistas, estando presente em $25 \%$ dos laboratórios. Como exemplo de geradores de resíduos A1 pode-se citar o Laboratório de Enfermagem, de Microbiologia, de Química Geral, de Química dos Solos, entre outros.

O grupo E representa os materiais perfurocortantes ou escarificantes, como exemplo:lâminas de barbear, agulhas, escalpes, ampolas de vidro, brocas, lâminas de bisturi, lancetas, micropipetas, 
lâminas e lamínulas, espátulas e todos os utensílios de vidro quebrados no laboratório (ex.: pipetas, tubos de coleta sanguínea, placas de Petri), entre outros (BRASIL, 2005).

\section{Tabela 3 - Resíduos biológicos: Grupo A.}

\begin{tabular}{cc}
\hline Tipo de resíduo & Número de laboratórios geradores \\
\hline A1 & 8 \\
A2 & 1 \\
A3 & 0 \\
A4 & 1 \\
A5 & 3 \\
\hline
\end{tabular}

Fonte: do autor (2014)

A Tabela 4 apresenta os principais resíduos do grupo $\mathrm{E}$ produzidos nos laboratórios. A opção "outros" foi indicada muitas vezes, visto que são diversos os materiais perfurocortantes utilizados, sendo impraticável elencar todos no questionário. Como exemplo de alguns materiais que foram citados nesta opção, tem-se: estiletes, canivetes, pinças, lâminas, entre outros.

\section{Tabela 4 - Resíduos biológicos: Grupo E.}

\begin{tabular}{cc}
\hline Tipo de resíduo & Número de laboratórios geradores \\
\hline Utensílios de vidros quebrados & 11 \\
Espátulas & 10 \\
Micropipetas & 9 \\
Lâmina de barbear & 9 \\
Ampolas de vidro & 8 \\
Agulhas & 7 \\
Brocas, lâminas de bisturi & 7 \\
Escalpes & 2 \\
Outros & 9 \\
\hline
\end{tabular}

Fonte: do autor (2014)

Os resíduos biológicos apresentam alto risco para a saúde e ao meio ambiente, tendo em vista o seu potencial de contaminação. Sendo assim, para o ambiente de trabalho ser um local seguro, todos os resíduos devem ser manipulados adequadamente. A Resolução RDC no 222/18 regulamenta as boas práticas de gerenciamento dos resíduos de serviços de saúde e se aplica aos geradores de resíduos, sejam eles públicos, privados, filantrópicos, civis ou militares, incluindo aqueles que exercem ações de ensino e pesquisa (BRASIL, 2018).

\section{Resíduo Radioativo}

Ao responder o questionário, nenhum dos professores colaboradores registrou a geração de resíduos radioativos, seja nos laboratórios que já estavam em funcionamento ou nos que ainda seriam implementados. Entretanto, não foi descartada a possibilidade de que, no futuro, esse tipo de resíduo possa vir a ser gerado dentro da Universidade, principalmente nos laboratórios da área de física, visto que a Instituição está em pleno crescimento e novos cursos estão sendo implantados, o que requer outros laboratórios além dos previstos inicialmente. 
Mesmo não constando no diagnóstico realizado, é importante ressaltar que os resíduos radioativos, também chamados de rejeitos radioativos, devem ser gerenciados obedecendo aos requisitos de proteção ao trabalhador, aos indivíduos em geral e ao meio ambiente, os quais são definidos pela Comissão Nacional de Energia Nuclear (COMISSÃO NACIONAL DE ENERGIA NUCLEAR, 2001).

\section{Resíduos Comuns}

Dentre todos os tipos de resíduos, o único identificado em todos os laboratórios pesquisados foi o resíduo comum. Sendo assim, percebe-se a importância que esse tipo de material representa e a atenção que deve ser destinada a ele. A Tabela 5 apresenta alguns dos resíduos comuns mais citados durante as entrevistas:

\section{Tabela 5 - Resíduos comuns.}

\begin{tabular}{|c|c|}
\hline Classe & Tipos de resíduos \\
\hline Papel & $\begin{array}{l}\text { Caixa de papelão, papel sulfite, jornal, } \\
\text { embalagens, papel toalha, entre outros. }\end{array}$ \\
\hline Plástico & $\begin{array}{c}\text { Copos descartáveis, embalagens, garrafa } \\
\text { PET, isopor, entre outros. }\end{array}$ \\
\hline Vidro & $\begin{array}{l}\text { Vidrarias em geral de laboratório e } \\
\text { embalagens de reagentes. }\end{array}$ \\
\hline Metal & $\begin{array}{l}\text { Embalagens de alumínio dos produtos, } \\
\text { esponja de aço, arame, entre outros. }\end{array}$ \\
\hline Orgânico & $\begin{array}{l}\text { Madeira, tecido, restos de alimentos, resíduos } \\
\text { de tipos de solos, entre outros. }\end{array}$ \\
\hline Rejeito & $\begin{array}{c}\text { Pilhas, baterias, resíduos de solda, entre } \\
\text { outros. }\end{array}$ \\
\hline
\end{tabular}

Fonte: do autor (2014)

Muitas vezes os resíduos comuns, por se tratarem de materiais que são produzidos no cotidiano, não são tratados com o devido cuidado que merecem. Entretanto, esses resíduos são produzidos em grande quantidade e isso faz com que se tornem prejudiciais ao meio ambiente, por isso a necessidade dos processos de segregação, acondicionamento, armazenamento e destinação correta dos mesmos. Além disso, muitos desses resíduos são recicláveis e podem ser transformados em matéria prima para novos produtos, evitando, assim, a extração de recursos naturais.

A partir das entrevistas e também da vivência em alguns dos laboratórios em funcionamento, percebeu-se que a separação dos resíduos comuns em recicláveis e não recicláveis, por mais simples que seja, ainda não estava sendo realizada. Ambos vinham sendo acondicionados, na maioria dos casos, de forma misturada e, assim, muitos dos materiais que poderiam ser reciclados acabavam tendo sua vida útil reduzida ao passo que eram descartados inadequadamente.

Nesse sentido é importante destacar que se os resíduos comuns forem descartados juntamente com resíduos perigosos, ocorrerá a contaminação de todo o material, fazendo com que aquele resíduo que poderia ter uma destinação simples, tenha que ser tratado de maneira especial. Por esse motivo, todos os resíduos devem ser devidamente segregados, a fim de evitar dificuldades no processo de manejo e custos elevados no momento da destinação final. 
Fotos tiradas no laboratório de Química Geral, como mostra a Figura 1, retratam a maneira incorreta com que a segregação dos resíduos era praticada, uma vez que ocorria a mistura dos resíduos.

\section{Figura 1: Lixo comum.}

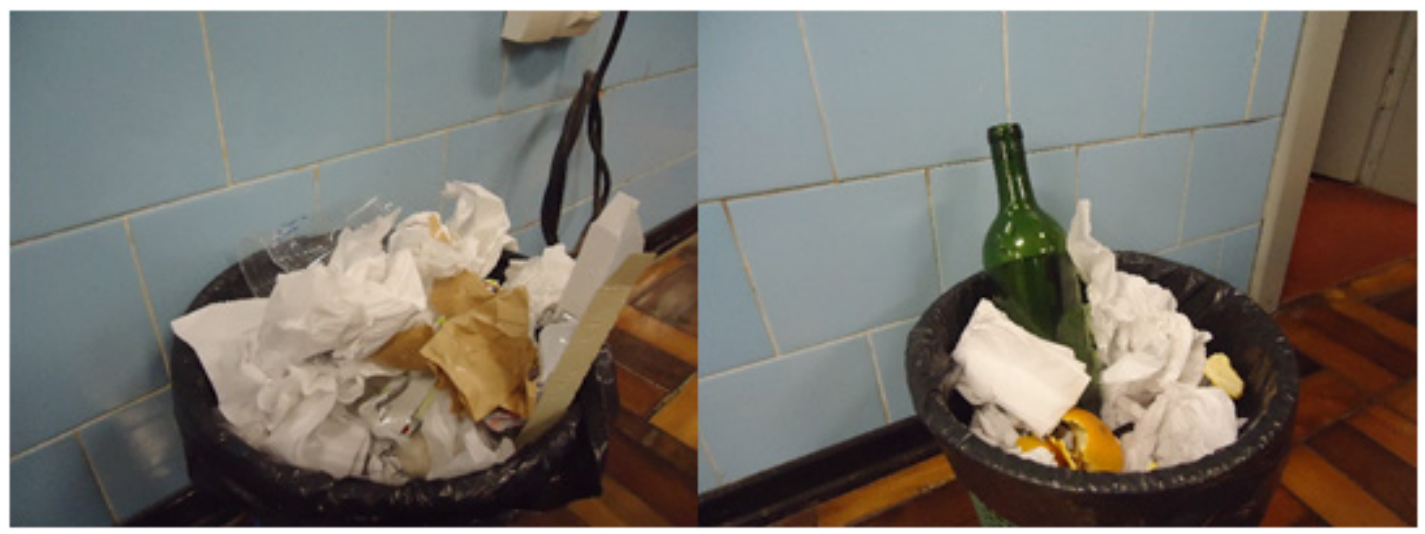

Fonte: do autor (2014)

Assim como foi descrito por Mesquita, Sartori e Fiuza (2011), percebe-se que o comportamento individual daqueles que utilizam esses espaços está muito aquém do necessário para o desenvolvimento de uma cultura sustentável dentro das instituições públicas, sendo necessária uma mudança comportamental de todos, tanto nas atitudes individuais como nas coletivas.

\section{Manejo dos Resíduos}

No questionário aplicado durante as entrevistas, também havia perguntas sobre a forma como era realizado o manejo dos resíduos sólidos nos laboratórios em funcionamento, bem como os procedimentos que seriam adotados nos demais laboratórios quando instalados em local definitivo. Procurou-se investigar, portanto, a maneira como os resíduos eram ou seriam segregados, acondicionados, armazenados, coletados, transportados, reutilizados e tratados.

Essa etapa das entrevistas foi de grande importância, visto que, independentemente dos tipos de resíduos sólidos produzidos, o manejo adotado é decisivo na medida em que determina se os resíduos gerados irão ou não causar impactos no meio ambiente. Ou seja, dependendo do manejo adotado, pode-se evitar impactos ambientais e garantir a saúde e a segurança dos usuários dos laboratórios.

De acordo com Schalch et al.(2002), o manejo inadequado de resíduos sólidos, independente da origem do resíduo, gera desperdícios, constitui ameaça constante à saúde pública e agrava a degradação ambiental, comprometendo a qualidade de vida das populações, especialmente nos grandes centros urbanos, devido à existência de inúmeros geradores de resíduos espalhados em diversos locais.

Considerando que a maior parte dos laboratórios pesquisados ainda não estava em funcionamento, as respostas obtidas nesta etapa das entrevistas consistem, na maioria dos casos, em ações que se pretende colocar em prática, o que mostra a intenção de dar o destino correto para os resíduos gerados.

A maioria dos entrevistados (75\%) afirmou que havia ou haverá segregação dos resíduos gerados no laboratório em funcionamento, e cerca de $71 \%$ disse que essa segregação é ou será realizada no ponto de geração. Entretanto, por não existir um PGRS, com normas bem planejadas e estabelecidas, a segregação nem sempre era adequada à melhor alternativa possível. 
Constatou-se que, normalmente, os resíduos químicos não eram descartados na rede de esgoto ou no lixo comum, porém sabe-se da existência de diversos casos de descarte inadequado dentro dos laboratórios, não só da Instituição estudada, mas também de inúmeras outras.

A partir de visitas feitas a alguns laboratórios, verificou-se que apenas os resíduos realmente mais perigosos eram estocados, de modo que todos os outros acabavam sendo neutralizados e descartados na rede de esgoto, uma vez que não existia um local adequado e com tamanho suficiente para armazenar tudo o que era produzido durante os experimentos.

As considerações acima retratam apenas algumas práticas adotadas na Universidade. Entretanto, segundo Schalch et al. (2002), são inúmeras as etapas que compõem o manejo dos resíduos sólidos, dentre as quais devem ser ressaltadas a forma de geração, acondicionamento na fonte geradora, coleta, transporte, processamento, recuperação e disposição final.

Em relação às normas de segurança do trabalho, verificou-se que os laboratórios ainda não possuíam um manual de segurança. A existência de normas sobre os procedimentos a serem adotados para garantir a saúde e a segurança dos usuários (professores, técnicos e estudantes) dos laboratórios é de vital importância e requer grande atenção, pois o ambiente de um laboratório pode abrigar diversas substâncias e equipamentos que oferecem grandes riscos de acidentes quando não manuseados corretamente. Na elaboração das normas de segurança, após serem identificados os resíduos que representam riscos ambientais aos usuários, devem ser indicados os Equipamentos de Proteção Coletiva (EPCs) e os Equipamentos de Proteção Individual (EPIs) necessários para o seguro funcionamento dos laboratórios.

A maioria dos entrevistados informou nunca ter ocorrido acidentes nos laboratórios. Entretanto, sabe-se que esses ambientes oferecem riscos à saúde dos trabalhadores e estudantes, e por isso necessitam de Manual de Segurança contendo as normas de trabalho, além do Mapas de Risco e Programa de Prevenção de Riscos Ambientais, de modo a eliminar ou ao menos reduzir os agentes causadores de riscos, prevenindo assim a ocorrência de acidentes e doenças ocupacionais.

No que diz respeito aos equipamentos de proteção, foi possível notar a falta de EPC's essenciais para a segurança de alguns laboratórios, como exemplo: chuveiro lava olhos, exaustor e capela de exaustão. Verificou-se, também, que apesar da falta de alguns EPI's, aqueles que eram fornecidos estavam adequados às atividades realizadas e possuíam o Certificado de Aprovação (CA), conferido por órgão responsável.

A partir de visitas in loco nos laboratórios que estavam em funcionamento, identificou-se os locais precários nos quais eram armazenados alguns dos resíduos produzidos (Figura 2). Os outros resíduos acabavam sendo descartados no lixo comum ou, após neutralização, nas pias dos laboratórios, pois não havia espaço suficiente para o armazenamento de tudo que era gerado.

Alguns materiais cortantes eram acondicionados de maneira totalmente incorreta e insegura, conforme mostra a Figura 3, sem nenhum tipo de proteção e expostos em local que qualquer pessoa poderia ter acesso, colocando em riscos os usuários do laboratório e principalmente o encarregado de realizar o manejo desses resíduos.

Um dos locais em que os reagentes eram armazenados dentro do laboratório, ficava logo acima do local utilizado como depósito dos resíduos. O restante dos reagentes ficava em um depósito dentro do laboratório, o qual também apresentava condições inapropriadas de segurança, como por exemplo a deficiência de ventilação.

As imagens acima e os resultados da pesquisa evidenciam a real necessidade de um PGRS para os laboratórios da UFFS - Chapecó, a fim de orientar e regulamentar o manejo dos resíduos. 
Figura 2 - Armazenamento Interno de Resíduos.

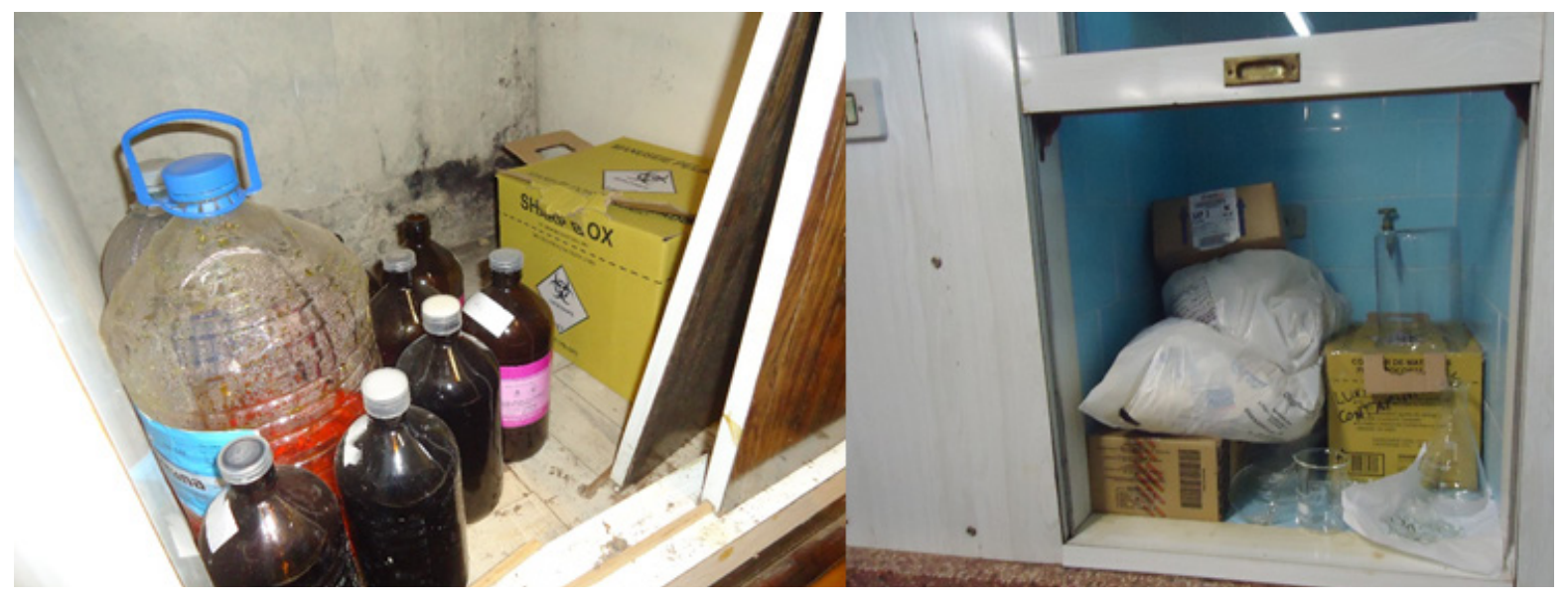

Fonte: do autor (2014)

\section{Figura 3 - Armazenamento Interno de Resíduos.}

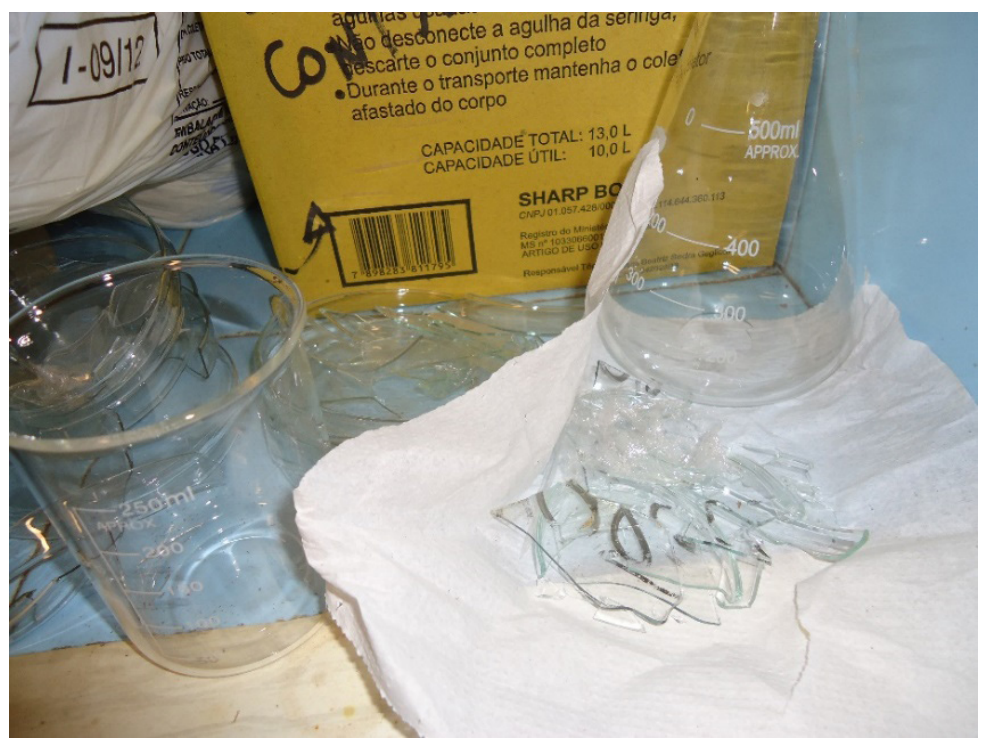

Fonte: do autor (2014)

\section{Plano de Gerenciamento de Resíduos Sólidos (PGRS)}

A partir da identificação dos resíduos gerados nos laboratórios provisórios e da estimativa dos resíduos que serão gerados nos laboratórios definitivos da Instituição, elaborou-se, como resultado final deste trabalho, um PGRS, com o intuito de propor as orientações necessárias para o manejo correto de todos os resíduos, incluindo as etapas de segregação, identificação das embalagens, acondicionamento, armazenamento interno e externo, coleta, transporte interno e externo, tratamento, destinação e disposição final.

O PGRS contempla ainda o Plano de Emergência, o qual apresenta as ações a serem adotadas em caso de vazamentos, derramamentos e acidentes que possam vir a acontecer com os resíduos, bem como as respectivas normas de saúde e segurança dos usuários. 


\section{Considerações finais}

Levando-se em consideração que a UFFS estava em fase de construção e consolidação de seus laboratórios definitivos no momento em que a pesquisa foi realizada, os resultados obtidos a partir da identificação dos resíduos foram de grande importância para a posterior elaboração de um PGRS, com o intuito de garantir o manejo adequado para todos os resíduos oriundos dos laboratórios de ensino e pesquisa, assim como garantir a minimização dos impactos gerados pelas atividades da Instituição.

A partir dos resultados deste trabalho, percebeu-se diversas dúvidas por parte de alguns dos responsáveis pelos laboratórios da Instituição quanto ao gerenciamento adequado dos resíduos. Além disso, a falta de espaço adequado nas instalações provisórias dos laboratórios, tinha como consequência o manejo inadequado dos resíduos, a falta de segurança para quem manipulava os mesmos e diversos riscos à saúde da população e ao meio ambiente.

Assim como a Universidade pesquisada, várias outras encontram-se na mesma situação, em instalações provisórias, ou mesmo definitivas, mas em condições inapropriadas de uso, colocando em risco a saúde dos seus trabalhadores, estudantes e o meio ambiente. Logo, percebe-se a necessidade de as Instituições de Ensino Superior adotarem um sistema de manejo adequado dos resíduos, pois isso permite eliminar ou reduzir os efeitos adversos que estes podem causar.

A identificação dos resíduos que são gerados nos laboratórios é fundamental para a elaboração de um PGRS que contemple o correto gerenciamento deles e promova ações corretivas em relação às práticas errôneas adotadas.

Igualmente importante e necessária é a estimativa dos resíduos que serão gerados em laboratórios que ainda não estão em funcionamento, uma vez que, a partir dela, é possível prever ações que deverão ser tomadas quando os resíduos passarem a ser produzidos. Essa estimativa possibilita a elaboração prévia de um PGRS, o que garante que as atividades nos novos laboratórios já iniciem de forma segura e salubre.

Espera-se que este estudo sirva de referência para que mais pesquisas nesse âmbito sejam desenvolvidas em outras universidades, tendo em vista a identificação dos resíduos produzidos e a disseminação de boas práticas de gerenciamento de resíduos.

\section{Comitê de Ética}

O questionário aplicado durante a execução desta pesquisa foi previamente submetido à aprovação pelo Comitê de Ética em Pesquisa (CEP) da Universidade Comunitária da Região de Chapecó, sendo aprovado sob o registro no 194/12.

\section{Referências}

ASSOCIAÇÃO BRASILEIRA DE NORMAS TÉCNICAS. NBR 10004: Classificação de Resíduos. Rio de Janeiro, 2004.

ALBUQUERQUE, Bruno Lins et al. Gestão de Resíduos Sólidos na Universidade Federal de Santa Catarina: Os Programas Desenvolvidos pela Coordenadoria de Gestão Ambiental. 
In: COLOQUIO INTERNACIONAL SOBRE GESTIÓN UNIVERSITARIA EN AMÉRICA DEL SUR, 10., 2010, Mar del Plata. Anais... . Mar del Plata: 2010. p. 1 12.Disponível em: <https://gestaoderesiduos.ufsc.br/files/2016/04/05_GRS-na-UFSCdesenvolvido-pela-coordenadoria-de-GA.pdf>. Acesso em: 14 set. 2019.

BRASIL. Ministério da Saúde. Agência Nacional de Vigilância Sanitária. Resolução RDC N²22 de 28 de março de 2018. Regulamenta as Boas Práticas de Gerenciamento dos Resíduos de Serviços de Saúde e dá outras providências. Disponível em: <http://portal. anvisa.gov.br/documents/10181/3427425/RDC_222_2018_.pdf/c5d3081d-b331-46268448-c9aa426ec410>. Acesso em: 14 set. 2019.

BRASIL. Resolução CONAMA no 358, de 29 de abril de 2005. Dispõe sobre o tratamento e a disposição final dos resíduos dos serviços de saúde e dá outras providências. Brasília, SEMA, 2005. Disponível em: <http://www2.mma.gov.br/port/conama/legiabre. cfm?codlegi=462>. Acesso em: 22 maio 2016.

BRASIL. Lei Federal no 12.305, de 02 de agosto de 2010. Institui a Política Nacional de Resíduos Sólidos; altera a Lei no 9.605, de 12 de fevereiro de 1998; e dá outras providências. Brasília, 2010.

Disponível em: <http://www.planalto.gov.br/ccivil_03/_ato2007-2010/2010/1ei/112305. $\mathrm{htm}>$. Acesso em: 22 maio 2016.

COMISSÃO NACIONAL DE ENERGIA NUCLEAR. Rejeitos Radioativos. Ministério da Ciência e Tecnologia. Rio de Janeiro, 2001. Disponível em: <http://www2. unifesp.br/nucleos/protecaoradiologica/download/rejeitos.pdf>. Acesso em: 25 maio 2016.

FERNANDES, L.O.; NUNES,J. A.; PORTO,M.F. S.. Contaminação química: respostas das instituições responsáveis e ações das populações atingidas no Brasil e em Portugal. Saúde Sociedade, São Paulo, v.25, n.1, 2016. Disponível em: <http://www.scielo.br/pdf/ sausoc/v25n1/1984-0470-sausoc-25-01-00218.pdf>. Acesso em: 27 maio 2016.

GERBASE, A.E.; COELHO, F. S.; MACHADO, P. F. L.. Gerenciamentos de resíduos químicos em instituições de ensino e pesquisa. Química Nova, São Paulo, v. 28, n. 1, 3, 2005. Disponível em: <http://quimicanova.sbq.org.br/imagebank/pdf/Vol28No1_3_001editoria28-1.pdf $>$. Acesso em: 22 maio 2016.

MESQUITA, E. G.; SARTORI, H. J. F.; FIUZA, M. S. S.. Gerenciamento de resíduos sólidos: estudo de caso em Campus universitário. Construindo, Belo Horizonte, v.3, n.1, 2011. Disponível em: <http://www.fumec.br/revistas/construindo/article/ download/1765/1131>. Acesso em: 25 maio 2016.

NOLASCO, F. R.; TAVARES, G. A.; BENDASSOLLI, J. A. Implantação de programas de gerenciamento de resíduos Químicos laboratoriais em universidades: 
Análise crítica e recomendações. Revista de Engenharia Sanitária e Ambiental, Rio de Janeiro, v.11, n. 2, 2006. Disponível em: <http://www.scielo.br/scielo.php?pid=S141341522006000200004\&script=sci_abstract\&tlng=pt $>$. Acesso em: 25 maio 2016.

SCHALCH, Valdir et al. Gestão e gerenciamento de resíduos sólidos. São Carlos: Universidade de São Paulo, 2002. Disponível em: <http://www.deecc.ufc.br/Download/ Gestao_de_Residuos_Solidos_PGTGA/Apostila_Gestao_e_Gerenciamento_de_RS_ Schalch_et_al.pdf>.Acesso em: 25 maio 2016.

VENTURI, Lilian; PEREIRA, Raquel da Silva. Gestão de Resíduos Sólidos em Universidade: Um Estudo a Partir da Política Nacional de Resíduos Sólidos. Revista Eletrônica de Administração, Online, v. 14, n. 1, p.180-196, jun. 2015. Disponível em: <http://periodicos. unifacef.com.br/index.php/rea/article/view/867/817>. Acesso em: 14 set. 2019. 